\title{
(-)-AMPELOPSIN F, DIMERSTILBENE COMPOUND FROM Dryobalanops oblongifolia AND ANTIMALARIAL ACTIVITY TEST
}

\author{
Indriani, ${ }^{1,4}$ Yoshiaki Takaya, ${ }^{2}$ N. N. T. Puspaningsih, ${ }^{3 *}$ \\ and N. S. Aminah ${ }^{3 *}$
}

The Dipterocarpaceae (dipterocarp) is one of a large family comprising 16 genera, about 600 species of which are widely distributed (76\%) in Malaysia and Indonesia. Dryobalanops comprises a small number of species. This genus is locally named kayu kapur [1,2]. As other genus in Dipterocarpacea, Dryobalanops has been known to be a rich source of phenolic compounds, especially stilbene oligomers [3-6] but there has never been a report on their antimalarial activity.

Previous studies have identified stilbene oligomers from Dryobalanops oblongifolia Dyer, namely (-)-ampelopsin A, a compound of dimer stilbenoid, and two compounds of trimer stilbenoid, namely cis- and trans-diptoindonesin B [3, 4]. This paper reports on a compound of dimer stilbene, (-)-ampelopsin F, from the acetone extract of the tree bark of D. oblongifolia. Test of its antimalarial activity showed an $\mathrm{IC}_{50}$ value of $0.001 \mu \mathrm{g} / \mathrm{mL}$, which makes it promising as an antimalarial compound.

The structure of (-)-ampelopsin F (1) was determined based on physical data and spectroscopic data, including UV, MS, NMR, 2D NMR, and also by comparison with published data. The antimalarial activity test was carried out according to the method of Trager and Jensen [7].

The melting point was determined on a micro melting-point apparatus, UV spectra was measured using a UV-Vis Shimadzu spectrometer in $\mathrm{MeOH}$, and ${ }^{1} \mathrm{H}$ and ${ }^{13} \mathrm{C}$ NMR spectra were recorder on a JEOL J-500 spectrometer operating at $500 \mathrm{MHz}\left({ }^{1} \mathrm{H}\right)$ and $125 \mathrm{MHz}\left({ }^{13} \mathrm{C}\right)$ using TMS as an internal standard. Optical rotatory was measured using a PerkinElmer 341 polarimeter. Gravitation column chromatography (GCC) was carried out using Merck Si gel 60 (70-200 mesh), vacuum liquid chromatography (VLC) and radial chromatography using Merck Si gel $60 \mathrm{GF}_{254}$, and thin-layer chromatography (TLC) using procoated Si gel plates (Merck kieselgel $60 \mathrm{~F}_{254} 0.25 \mathrm{~mm}$ ). Solvents used in this research were of analytical and technical grade and were distilled before use.

The tree bark of D. oblongifolia Dyer was obtained from Gunung Mali, Tempunak, Sintang, West Kalimantan, in December 2012. The specimen was identified at Biological Research Center, LIPI, Bogor, Indonesia, and a voucher specimen has been deposited at the herbarium.

The powdered tree bark of Dryobalanops oblongifolia $(5 \mathrm{~kg})$ was macerated with acetone for $2 \times 24 \mathrm{~h}$ and then concentrated under reduced pressure to give a gummy brownish extract. The extract was divided into acetone-diethyl ether soluble and insoluble fractions. The acetone-diethyl ether soluble fraction (48 g) was fractionated using VLC ( $n$-hexane-ethyl acetate, increasing polarity) to give four major fractions A-D. From TLC analysis, fraction D (3.2 g) was chosen for further analysis. Fraction D was GCC refractionated repeatedly using $n$-hexane-ethyl acetate 5:5 - ethyl acetate $100 \%$ to yield fractions D1-D3. Fraction D1, on repeated purification using radial chromatography with chloroform-methanol (9:1), yielded compound $1(14.8 \mathrm{mg})$.

Compound 1 was obtained as an amorphous brown solid, mp $220-222^{\circ} \mathrm{C}(\mathrm{dec}),[\alpha]_{\mathrm{D}}^{25}-2^{\circ}$. The molecular formula, $\mathrm{C}_{28} \mathrm{H}_{22} \mathrm{O}_{6}$, of compound 1 was established based on HR-FAB-MS $\left(m / z 454.1416[\mathrm{M}]^{+}\right)$, corresponding to a resveratrol dimer.

1) Doctoral Student of Mathematic and Natural Sciences, Faculty of Science and Technology, Universitas Airlangga, Kampus C UNAIR, J1. Mulyorejo, Surabaya, 60115, East Java, Indonesia; 2) Faculty of Pharmacy, Meijo University, 468-8503, Tempaku Nagoya, Japan; 3) Department of Chemistry, Faculty of Science and Technology, Faculty of Science and Technology, Universitas Airlangga, Kampus C UNAIR, J1. Mulyorejo, Surabaya, 60115, East Java, Indonesia, e-mail: nanik_sa2000@yahoo.com; 4) Department of Chemistry, Universitas Tadulako, Jalan Soekarno Hatta Tondo, 94118, Palu, Indonesia. Published in Khimiya Prirodnykh Soedinenii, No. 3, May-June, 2017, pp. 474-475. Original article submitted August 24, 2015. 